\title{
Properties of SBR/NR Blend: The Effects of Carbon Black/Silica (CB/Si) Hybrid Filler and Silane Coupling Agent
}

\section{Anand G ( $\square$ anand.g@pec.edu )}

Achariya College of Engineering Technology Department of Mechanical Engineering https://orcid.org/0000-0001-6529-7341

S. Vishvanathperumal

SA Engineering College

\section{Research Article}

Keywords: Natural rubber/SBR, Carbon black/silica, SCA, Mechanical properties, Scanning electron microscopy

Posted Date: September 23rd, 2021

DOI: https://doi.org/10.21203/rs.3.rs-922308/v1

License: (c) (i) This work is licensed under a Creative Commons Attribution 4.0 International License. Read Full License 


\section{Abstract}

In the current research, investigation of natural rubber (NR)/styrene butadiene rubber (SBR) reinforced with carbon black (CB)/silica (Si) and with and without silane coupling agent (Si69) was analyzed. The total hybrid filler (CB/Si) concentration in the composite was fixed at 50 phr. Cure characteristics, mechanical properties and surface morphology were examined. The addition of a silane coupling agent improves the mechanical properties of NR/SBR rubber composites reinforced with CB/Si hybrid fillers. Compared with NR/SBR composites with Si69, addition of 0/50 CB/Si resulted in 53\% decrease of tensile strength and $81 \%$ increase of elongation at break, superior to that of NR/SBR composites without Si69. When Si69 was used as a binding agent, the scanning electron micrograph (SEM) of the tensile fractured surface clearly shows the better dispersion of hybrid fillers in the NR/SBR matrix.

\section{Introduction}

The development in industries and advancement in economic need results in never-ending demand for newer as well as low-cost materials. The polymer blending was a universal technology commonly used in the development of a newer product with superior properties. Because of its ability to adjust its shape crystallise under stretching, natural rubber (NR) has exceptional tensile properties [1-2], as well as better stress relief, electrical insulation, high abrasion, and fatigue resistance. NR, on the other hand, was vulnerable to ozone and had a lower resistance to petroleum-based fuels and oils [3]. Because of its low cost, styrene butadiene rubber (SBR) was a commonly used rubber and was the first synthetic rubber considered for manufacturing rubber components. Despite their strong mechanical properties, SBRs have low abrasion resistance when exposed to conditions such as moisture, ozone, and sunlight. The presence of a double bond in the main polymeric chain was responsible for this [4-6]. Due to their excellent mechanical and other engineering properties, NR and SBR blends are very appealing nowadays. Natural rubber (NR) offers stronger strength, reduced heat build-up, and better low-temperature performance than styrene butadiene rubber (SBR). SBR has superior crack resistance, wet grip, and weather resistance than NR. As a result, tyre manufacturers frequently use NR/SBR mixtures. However, there are no defined principles for creating a compound for an NR/SBR blend in order to achieve a specific set of mechanical properties [7]. SBR and NR are partially miscible. In SBR-NR systems, the largest amount of interface was observed at a 50:50 blend composition [8]. Blends of natural rubber and butadiene rubber (NR/BR) or natural rubber and styrene-butadiene rubber (NR/SBR) are used in standard tyre formulations for cars and other vehicles. The blends of NR and SBR have been in use for a longer time period in many applications which also reduces the compounds cost [9-10]. Studies have been made by many researchers of such blends and the different properties are examined in detail [11-12]. Different filler materials, such as carbon black (CB) and silica (Si), are commonly used to enhance the mechanical properties of rubber composites [13-14].

$\mathrm{CB}$ and $\mathrm{Si}$ have been commonly used as reinforcement materials in most engineering applications to improve the degree of rubber compounds. Tensile strength, tear strength, abrasion resistance, and modulus are all improved when CB is reinforced with either natural or synthetic rubber [15]. As compared 
to silica reinforcement, $\mathrm{CB}$ reinforced rubber composites have a higher modulus. Whereas, silica offers properties such as improved tear strength, adhesion behavior, abrasion and aging resistance [16]. In comparison to CB reinforcement, silica reinforcement reduces rolling resistance, wet grip, and abrasion resistance in tyre treads [17]. Since carbon black and silica both have their own set of benefits, using hybrid fillers (a mix of CB and silica) in rubber compounds can give you the best of both worlds. Wires and cloth coatings, tyre tread, rubber-covered belts, conveyor belts, hoses, engine mounts, cable jackets, and bumper strips can all be made with CB-reinforced rubber composites that have silica added to them [18-19]. In the polymeric industry, silica served as non-black reinforcing filler. In general, silica has a lot of polar groups on its surface, which helps the filler-filler interaction by hydrogen bonds to be stronger [20]. As compared to $\mathrm{CB}$, adding silica to the rubber composite causes a slew of problems, most notably poor dispersion. The introduction of a particular coupling agent [21] will overcome the problems associated with silica incorporation.

To improve the mechanical properties of silica-filled rubber composites, silane coupling agents are used. It is required to neutralize silanol groups on silica's surface while also increasing silica distribution in rubber blends. Many studies have been done on the impact of silane coupling agents on the mechanical and physical properties of rubber composites [22-27]. From the literature, it was clear that not much systematic research work have been reported with $\mathrm{CB} / \mathrm{Si}$ hybrid filler on the properties of NR/SBR composites. In this study we discuss the influence of hybrid filler ( $\mathrm{CB} / \mathrm{Si})$ on the cure characteristics, mechanical properties and morphology of 50/50 NR/SBR composites. The total hybrid filler (CB/Si) concentration in the composite was fixed at $50 \mathrm{phr}$. $\mathrm{CB} / \mathrm{Si}$ is not added beyond $50 \mathrm{phr}$ due to the formation of cluster in rubber matrix and cost factor.

\section{Experimental}

\subsection{Materials and Methods}

The natural rubber (NR-RSS1) was purchased from Asian Rubber, Ambattur, Chennai, India and SBR (SBR1502) was procured from Arihant Reclamation Pvt. Ltd., Delhi, India. The reinforcement (silica (SUPERSIL 140), carbon black (N330)), silane coupling agent (Si69), and curatives (zinc oxide, stearic acid, sulphur, mercaptobenzothiazyl disulphide (MBTS), tetramethylthiuram disulphide (TMTD) and processing oils) were of commercial grade and purchased from Vignesh Chemicals, Chennai, India.

The alteration of silica with TESPT was carried out in solution to see how SCA affects silica reactivity and to eliminate any confounding effects of the NR/SBR matrix. In a three-necked flask, $10 \mathrm{~g}$ of silica were dispersed in $300 \mathrm{~mL}$ of toluene, followed by $1.0 \mathrm{~g}$ of SCA. The silanization reaction was carried out at $80^{\circ} \mathrm{C}$ for 12 hours with constant stirring. After that, the result was centrifuged and washed with ethanol and toluene multiple times to remove the ungrafted TESPT before being dried at $50^{\circ} \mathrm{C}$.

The NR/SBR composite was formulated with a blend ratio of 50/50 as shown in Table 1. A two-roll mill at $50^{\circ} \mathrm{C}$ was used to make the rubber compounds. NR was masticated for 4 minutes before being blended 
with SBR for another 4 minutes in the first stage. Before incorporating constituent or reinforcing materials, it was important to soften the compound blend. The CB/Si was incorporated in the NR/SBR blend with two major portions. Half of the constituents (zinc oxide and stearic acid) will be induced together after half of the $\mathrm{CB} / \mathrm{Si}$ is added. The other half of $\mathrm{CB} / \mathrm{Si}$ and its constituents were treated in the same way. In the final stage, the sulphur was gradually added followed by MBTS and TMTD into the blend respectively. The total compounding time was done approximately from 25 to $35 \mathrm{~min}$ and compound dumping temperature were range from 50 to $80^{\circ} \mathrm{C}$. The prepared samples cure characteristics were investigated using a Monsanto Oscillating Disc Rheometer (ODR 2000) at $160^{\circ} \mathrm{C}$. The rubber compound was then compressed and moulded at $160^{\circ} \mathrm{C}$ in an electrically heated hydraulic press in accordance with the cure times [28-30]. A die cutter was used to make the dumbbell and nicked tab endspecimens.

Table 1

Formulation for SBR/NR Blend with and without Si69

\begin{tabular}{|lll|}
\hline Constituents (phr) & Blend ratio & With Si69 \\
\cline { 2 - 3 } & Without Si69 & 50 \\
\hline SBR & 50 & 50 \\
\hline NR & 50 & $50 / 0,40 / 10,30 / 20,20 / 30$, \\
\hline CB (N330)/silica (SUPERSIL & $50 / 0,40 / 10,30 / 20,20 / 30$, & $10 / 40,0 / 50$ \\
\hline 140) & $10 / 40,0 / 50$ & 3 \\
\hline Si69 & - & 5 \\
\hline Zinc oxide & 5 & 2 \\
\hline Stearic acid & 2 & 2 \\
\hline Sulphur & 2 & 1 \\
\hline MBTS & 1 & 1 \\
\hline TMTD & 1 & 5 \\
\hline Processing oil & 5 & 2 \\
\hline
\end{tabular}

\subsection{Cure behaviors}

The cure behaviour of the unvulcanized rubber samples was carried out as per ASTM D-2084 standard by oscillating disc rheometer at $160^{\circ} \mathrm{C}$, oscillation arc of $0.5^{\circ}$ and 100 cycles per minute $(1.66 \mathrm{~Hz})$ conditions.

\subsection{Mechanical properties}


According to the requirements, dumbbell and nicked tab end shaped samples are cut from the moulded sheets. Tensile and tear checking was carried out in accordance with ASTM D 412 and ASTM D 624. Dak System Inc is used to perform tensile and tear tests at a crosshead speed of $500 \mathrm{~mm} / \mathrm{min}$ (model: T72102). The tensile strength, elongation at break and modulus were determined by Universal testing machine at $23^{\circ} \mathrm{C}$. The average values of six replicate measurements were used to arrive at the final outcome.

The samples hardness was determined using an ASTM D 2240 Shore-A Durometer. The hardness of composites was evaluated by the penetration of the Durometer tester into the rubber material, kept under formerly set conditions. The sheets with an effective thickness of $6 \mathrm{~mm}$ were used to test hardness.

The rebound resilience tests were carried out using a vertical rebound resilience tester in accordance with ASTM D 2632 guidelines. The rolling slide test was used to assess the abrasion resistance, which was determined as the relative volume loss from the wear test using a Zwick DIN Abrader (model: 6102), as per the ASTM D-5963 standard testing technique. A $0.1 \mathrm{kN}$ force was given to the rolling sliding cylinder on $\mathrm{SiC}$ paper in this experiment. A minimum of five measurements were taken, with the average values reported.

\subsection{Crosslink density}

Cure test pieces of $20 \times 20 \times 2 \mathrm{~mm}$ were weighed and immersed in a glass vessel containing toluene (50 $\mathrm{mL}$ ) at $23^{\circ} \mathrm{C}$. To avoid oxidation, the vessel was kept in a dark place. The samples were removed from the glass diffusion vessel and tissue paper was used to remove the excess toluene from the sample. To prevent toluene evaporation, the samples were stored in a closed vessel and the weights of the swollen samples were calculated. The sample was then re-immersed in toluene and the process was repeated until the sample reached a constant swollen weight. For the volume fraction of swelling rubber, the sample was de-dried in a vacuum at room temperature to a constant weight. The Flory-Rehner equation [31] was used to compute the molecular weight between two crosslinks $(\mathrm{Mc})$ using the swelling data. 
$M_{c}\left(\frac{g}{m o l}\right)=\frac{-\rho_{p} V_{s} V_{r}^{1 / 3}}{\ln \left(1-V_{r}\right)+V_{r}+\chi V_{r}^{2}}$

$V_{r}=\frac{1}{1+Q_{m}}$

Where, $\rho=$ density of the rubbers, $V_{s}=$ molar volume of the toluene, $V_{r}=$ volume fraction of the swollen rubber, $\chi=$ interaction parameter of the NR/SBR rubber, and $\mathrm{Q}_{\mathrm{m}}=$ weight swell of the $\mathrm{SBR} / \mathrm{NR}$ rubber blends in toluene. The degree of crosslinking density (v) is given by;

$v\left(\frac{m o l}{c^{3}}\right)=\frac{1}{2 M_{c}}$

The degree of crosslinking density of NR/SBR composites was determined using the following constant values.

$\rho(\mathrm{SBR})=0.921 \mathrm{~g} / \mathrm{cm}^{3}$,

$\rho(\mathrm{NR})=0.912 \mathrm{~g} / \mathrm{cm}^{3}$,

$\chi(\mathrm{NR} / \mathrm{SBR})=0.3557[32]$, and

$\mathrm{V}_{\mathrm{s}}=106.29 \mathrm{~cm}^{3} / \mathrm{mol}$

\subsection{Scanning electron microscopy (SEM)}

With an acceleration voltage of $3 \mathrm{kV}$ and a film of gold over it, a scanning electron microscope (Hitachi S2500 , Japan) was used to research the surface morphology of the tensile fractured surface.

\section{Results And Discussion}

\subsection{Cure behavior}

Figure 1 (a-d) depicts the cure behaviours (optimum cure time, scorch time, minimum torque, and maximum torque) of $\mathrm{CB} / \mathrm{Si}$ filler filled NR/SBR composites with and without silane coupling agent. The graph for the cure time is shown in Fig. 1 (a). The optimal cure time for both composites increases as the silica content increases. This was due to the presence of the silanol group in it [33]. Silica's surfaces are normally hydrophilic and polar. It also has a high tendency for absorbing moisture, which has a negative impact on the rubber composites' cure properties [34]. Figure 1 (a) shows that when a silane coupling agent was added to an NR/SBR composite with a similar composite ratio, the optimum cure time $\left(t_{c 90}\right)$ was shorter than when the silane coupling agent was not added. The composites with the presence of silanol groups which results in causing less hydrophilic characteristic, thus ensures a faster optimum cure time [35]. The silanol groups in sulfur-cured rubbers can cause accelerator adsorption, resulting in a delay in the vulcanization reaction and, as a result, a loss in crosslinked density [36]. The graph for scorch time was shown in Fig. 1 (b). The scorch time of hybrid filler-filled NR/SBR composites with and without silane coupling agent increases as the concentration of silica in the composite increases. When comparing composites with and without Si69, it was discovered that composites with Si69 have a longer scorch time $\left(t_{2}\right)$, indicating that there is good reaction between the Si69-silica-NR/SBR compounds in the 
composite. When the silica content is high, the amount of Si69 utilised in this study is thought to be sufficient (as the SBR, NR, and Si69 are constant except for silica content). As a result, the reaction between silica-Si69-NR was slightly increased. The NR/SBR tends to adsorbed on the silica surface in mixes without Si69, preventing the silica from adsorbing the accelerator and thereby reducing scorch time. When silica concentration is high, especially greater than $30 \mathrm{phr}$, the scorch time increases steadily. The steady increase in scorch time when silica concentration is larger than $30 \mathrm{phr}$ could be due to the fact that these compounds have had reduced heat history during mixing.

The graph for the minimum torque was shown in Fig. 1 (c). With an increase in silica concentration, the minimum torque of NR/SBR composites filled with hybrid filler with and without silane coupling agent increases. However, when comparing the composites with and without silane coupling agent, the composites with silane coupling agent exhibit a lower torque at all ratios, indicating that they are more processable. The graph for the maximum torque was clearly shown in Fig. 1 (d). From the figure it was clear that the maximum torque for NR/SBR hybrid composites with and without SCA was enhanced with an increase in silica concentration. Incorporation of hybrid fillers reduces the movement of the macromolecular chains in the composites, henceforth increases the maximum torque. However, when compared to NR/SBR composites without silane coupling agent, hybrid filler reinforced NR/SBR composites with silane coupling agent have a higher maximum torque value. The increased interaction between the hybrid filler and the NR/SBR matrix, especially in the presence of a silane coupling agent, may be responsible for the increased maximum torque.

\subsection{Mechanical properties}

From Fig. 2 to 7, the mechanical properties of CB/Si hybrid fillers reinforced NR/SBR composites with and without silane coupling agent are shown. Figure 2 shows the tensile strength of NR/SBR composites filled with hybrid fillers with and without a silane coupling agent.The figure clearly shows that both composites follow the same pattern, with the tensile strength of the composite decreasing as the silica content rises. The poor interaction of hybrid filler with NR/SBR rubber, as well as the rise in silica-silica interaction, resulted in a decrease in tensile strength at higher silica concentrations. Furthermore, as compared to the dispersion of carbon black, the dispersion of silica in rubber blends was very poor. This was due to the fact that silica forms a tight hydrogen bond, causing reinforcing material to clump together. The tensile strength of the hybrid composites was improved to a greater extent with the addition of a silane coupling agent. It was also apparent from the results that the composite with silane coupling agent had higher tensile strength than the composite without silane coupling agent at a comparable ratio of hybrid fillers (especially when the concentration of silica was more). The reinforcing material and the silane coupling agent formed a stable bond (Si-O-Si) when the silane coupling agent was incorporated into the composite [37]. The presence of a silane binding agent improved the interaction of hybrid fillers in the NR/SBR matrix, resulting in better dispersion. By lowering the interfacial energy between the stages, the hybrid filler's interfacial adhesion to the NR/SBR matrix improves.

The graphs for 100 percent modulus and elongation at break of hybrid composites with and without silane coupling agent are shown in Figs. 3 and 4. With increasing silica concentration, the 100 percent 
modulus tends to decrease, while the elongation at break tends to increase. The matrix-filler interaction decreases as the concentration of silica increases. In contrast, the modulus of hybrid composites with silane coupling agent is higher than that of composites without silane coupling agent at equivalent composite ratios. This was due to the presence of a silane binding agent, which increased cross-link density and improved filler dispersion. The elongation at break values increase with increasing silica concentrations when a silane coupling agent is added. This is because the silane coupling agent aided chemical bonding between the hybrid filler and the NR/SBR matrix, increasing elongation at break values [38]. Figures 5 and 6 , clearly indicates the hardness and rebound resilience of hybrid fillers reinforced NR/SBR composites with and without silane coupling agent. The hardness of the composite tends to decreases whereas the rebound resilience increases with the increase in the concentration of silica in it. Lower crosslink density (as illustrated later in Fig. 8) of the composite was responsible for the minimum hardness. This was because, as the crosslink density of the composite decreases, the harder matrix turns into a softer one [39-40]. The increase in the concentration of silica leads in decrease in the rubber-filler interaction. Nevertheless, at a similar composite ratio, the hardness and rebound resilience of hybrid composite with silane coupling agent shows a greater value as compared to the composite without silane coupling agent [41].

The Fig. 7, show the graph for the abrasion loss of hybrid NR/SBR composites with and without SCA. The graph shows that as the concentration of silica increases, the abrasion resistance decreases. The abrasion resistance of the composites was measured by the friction coefficient and by the modulus of the composite [42]. The lower frictional coefficient and higher modulus indicates that the composite have a better abrasion resistance. As compared to composites with mediocre filler dispersion, the composites with excellent filler dispersion were said to have improved abrasion properties [43-46]. As a result, the histrionic reduction in abrasion resistance at high silica content was expected to be due to weak silica dispersion or a heavy filler-filler relationship [47].

The Fig. 8, show the graph for the crosslinking density of hybrid NR/SBR composites with and without SCA. Increases in silica concentration result in a decrease in filler-rubber interaction (increases in silicasilica interaction), affecting the crosslinked density value [48-51]. The tensile strength, tensile modulus, elongation at break, and hardness of hybrid fillers filled NR/SBR blends with Si69 are higher than those of NR/SBR blends without Si69 at similar blend ratios. In the presence of Si69, this is simply owing to enhanced filler dispersion and greater crosslinked density. The Si69 significantly reduced filler-filler interaction, resulting in enhanced rubber-filler interaction and improved filler dispersion.

\subsection{Scanning electron microscopy}

The Fig. 9a-b shows the SEM micrographs of tensile fractured specimen reinforced with hybrid fillers with and without silane coupling agent at 20/30 composite ratio. Figure 9 (a) shows a rougher surface with numerous tear lines, indicating that more energy was needed to break the composite than Fig. 9 (b), which was nearly smooth. This is because the presence of a silane coupling agent improves the interaction of the CB and silica with the NR and SBR rubber matrix. The uniformly distributed hybrid fillers in NR/SBR matrix have an ability to resist the crack initiated and propagates which results in better 
tensile property of the composite [52]. The addition of the silane binding agent to the composite improves filler dispersion and decreases the silica-silica interface, resulting in improved matrix-reinforcing material interaction.

\section{Conclusions}

The optimum cure time of hybrid fillers reinforced NR/SBR composites with silane coupling agent was less than the composite without silane coupling agent, according to the report. This was attributed to the decrease in curative adsorption phenomena observed on the silica surface. The scorch time of the hybrid filler reinforced NR/SBR composites with silane coupling agent is higher. With increasing silica concentration, the minimum and maximum torque for the composite with and without silane coupling agent increases. Hybrid filler reinforced NR/SBR composites with silane coupling agent had higher tensile strength, modulus, elongation at break, hardness, rebound durability, and abrasion resistance than composites without silane coupling agent.This was due to the composite's improved matrix-filler interaction due to the presence of the silane coupling agent. The presence of silane coupling agent in hybrid fillers reinforced NR/SBR composites is revealed by SEM micrographs, which reveal better dispersion of the hybrid fillers in the NR/SBR matrix.

\section{Declarations}

\section{Competing Interests}

None of the authors have any relevant financial or non-financial competing interests and any conflict of interest to publish the article.

\section{* Conflict of Interest}

The authors declare no conflict of interest.

\section{* Compliance with ethical standards}

No, all testing are conducted in this study as per ASTM standards.

\section{* Consent to participate}

The authors declare the no objection of consent to participate

\section{* Consent for Publication}

The authors declare the no objection of consent to publication

\section{* Availability of data and material}

All data generated or analyzed during this investigation are included in this published article. 


\section{* Funding statement}

Not applicable

\section{* Author contributions}

1. G. Anand - Corresponding Author - First Author - Fabricated the composite samples and conducted the testing as per the ASTM standard and have written the manuscript, both authors read and approved the manuscript.

2. S. Vishvanathperumal - Second Author - Helped in Fabrication the samples and conducted the testing as per the ASTM standard and helped in writing the manuscript, both authors read and approved the manuscript.

\section{*Acknowledgments}

The authors are highly grateful to Achariya College of Engineering Technology, Pondicherry \& SA Engineering college, Chennai, India for their kind support in providing the time for research for academic interest.

\section{* Disclosure of potential conflicts of interest}

Not applicable

* Research involving Human Participants and/or Animals

Not applicable

* Informed consent

Not applicable

\section{References}

[1] Arroyo M, Lopez-Manchado MA, Valentin JL, Carretero J.Composite Science and Technology2007, 67, 1330-1339.

[2] Khang TH,Ariff ZM. International Polymer Processing2014, 29, 325-331.

[3] Nagdi K, Rubber as an Engineering Material: Guideline for Users, Hanser Publishers: Munich, New York, 1993.

[4] Franta I, Elastomers and Rubber Compounding Materials: Manufacture, Properties and Applications. Elsevier, Amsterdam, 1989.

[5] Morton M, Rubber Technology. Springer Science Business Media, Dordrecht, 1999.

[6] Morikawa A, Min K, White JL.International Polymer Processing1989, 4, 23-31. 
[7] Rani Joseph, K. E. George, D. Joseph Francis, Journal of Applied Polymer Science 35 (4), 1988, 10031017

[8] Douglas J. Hourston, Mo Song, Journal of Applied Polymer Science 76 (12), 2000, 1791-1798

[9] George SC, Ninan KN, Greonincks G, Thomas S. Journal of Applied Polymer Science2000, 78, 12801283.

[10] Barlow FW, Rubber Compounding, Principles, Materials and Techniques. Marcel Dekker, New York, 1993.

[11] Fayt R, Jerome R, Teyssie PH.Journal of Polymer Science Part B: Polymer Physics1982, 20, 12091217.

[12] Ismail H, Hairunezam HM. European Polymer Journal2001, 37, 39-44.

[13] Choi SS, Ha SH.Journal of Industrial and Engineering Chemistry2009, 15, 167-170.

[14] Park SJ, Seo MK, Nah C. Journal of Colloid and Interface Science2005, 291, 229-235.

[15] Choi SS, Nah C, Jo BW.Polymer Internationa/2003, 52, 1382-1389.

[16] Hashim AS, Azahari B, Ikelda Y, KohjiyaS.Rubber Chemistry and Technology1998, 71, 289-299.

[17] Brinke JWT, Debnath SC, Reuvekamp LAEM, Noorermeer JWM.Composites Science and Technology2003, 63, 1165-1174.

[18] Evans LR, Fultz WC, Huber JM.Rubber World1998, 219, 38.

[19] Okel TA, Waddell WH.Rubber Chemistry and Technology1994, 67, 217-236.

[20] Phewphong P, Saeoui P, Sirisinha C.Polymer Testing2008, 27, 873-880.

[21] Suzuki N, Ito M, Yatsuyanagi F.Polymer2005, 46, 193-201.

[22] Poh BT, Ng CC.European Polymer Journa/1998, 34, 975-979.

[23] Jesionowski T, Krysztafkiewicz A.Applied Surface Science2001, 172, 18-32.

[24] Nakajima N, Shieh WJ, Wang ZG.International Polymer Processing1991, 6, 290-296.

[25] Kim KJ,VanderKooi J,International Polymer Processing,2003, 18, 156-165.

[26] Kim KJ,Vanderkooi J.International Polymer Processing2004, 19, 364-373.

[27] Ismail H, Ishiaku US, Ishak ZAM, Freakley PK.European Polymer Journa/1997, 33, 1-6. 
[28] T. Kurian, K. E. George, D. J . Francis, Die Angewandte Makromolekulare Chemie 162 (1988) 123 $-134$

[29] Benjamin Zirnstein, Dietmar Schulze, Bernhard Schartel, Thermochimica Acta, 673, 2019, 92-104 [30] Abrar Ahamad, Pradeep Kumar, Composites Communications 22 (2020) 100440

[31] Flory, P. J.; Rehner, J. J Chem Phys 1943, 11, 512.

[32] Azreen Izzati Dzulkifli, Che Mohamad Som Said, Chan Chin Han, Ahmad Faiza Mohd, Advanced Materials Research 2015, 1134, 75-81.

[33] Idrus SS, Ismail H, Palaniandy S. Polymer PlasticsTechnology and Engineering2009, 48, 925-931.

[34] Ansarifar A, Shiah SF, Bennett M.International Journal of Adhesion and Adhesives2006, 26, 454-463.

[35] Yan H, Sun K, Zhang Y, Zhang Y.Polymer Testing 2005, 24, $32-38$.

[36] Nik Z. Noriman, Hanafı Ismail, Journal of Applied Polymer Science 2012, 124, 19-27.

[37] Soh, T.C., Yoong, S.S. Journal of Rubber Research 2021, 24, 165-174.

[38] Voet A, Morawski JC, Donnet JB. Rubber Chemistry and Technology1977, 50, 342-355.

[39] Vishvanathperumal S, Anand G. Silicon 2020, 12, 1925-1941.

[40] Vishvanathperumal S, Gopalakannan S. Applied Mechanics and Materials 2016, 852, 16-22.

[41] Radabutra, S., Khemthong, P. \& Saengsuwan, S. Journal of Rubber Research 2021, 24, 157-163.

[42] Vishvanathperumal S, Navaneethakrishnan V, Gopalakannan S. Journal of Advanced Microscopy Research 2018, 13, 469-476.

[43] Choi SS. Journal of Applied Polymer Science2002, 83, 2609-2616.

[44] Vishvanathperumal S, Gopalakannan S. Polymer Korea 2017, 41, 433-442.

[45] Vishvanathperumal S, Gopalakannan S. Silicon 2019, 11, 117-135.

[46] Senthilvel K, Vishvanathperumal S, Prabu B, John Baruch L. Polymers and Polymer Composites2016, 24, 473-480.

[47] Salehi, M.M., Khalkhali, T. \& Dourbash, A.R. Journal of Rubber Research 2018, 21, 165-181.

[48] Choi, S. -S. Polym Test 2002, 21, 201. 
[49] Vishvanathperumal S, Navaneethakrishnan V, Anand G, Gopalakannan S, Advanced Science, Engineering and Medicine 2020, 12, 632-642

[50] Vishvanathperumal S, Anand G, Silicon (2020). https://doi.org/10.1007/s12633-020-00792-9

[51] Vishvanathperumal S, Anand G, Silicon (2021). https://doi.org/10.1007/s12633-021-01138-9

[52] Raa Khimi Shuib, Rashid Shamsuddin, Journal of Applied Polymer Science, 138 (36), 50905

\section{Figures}
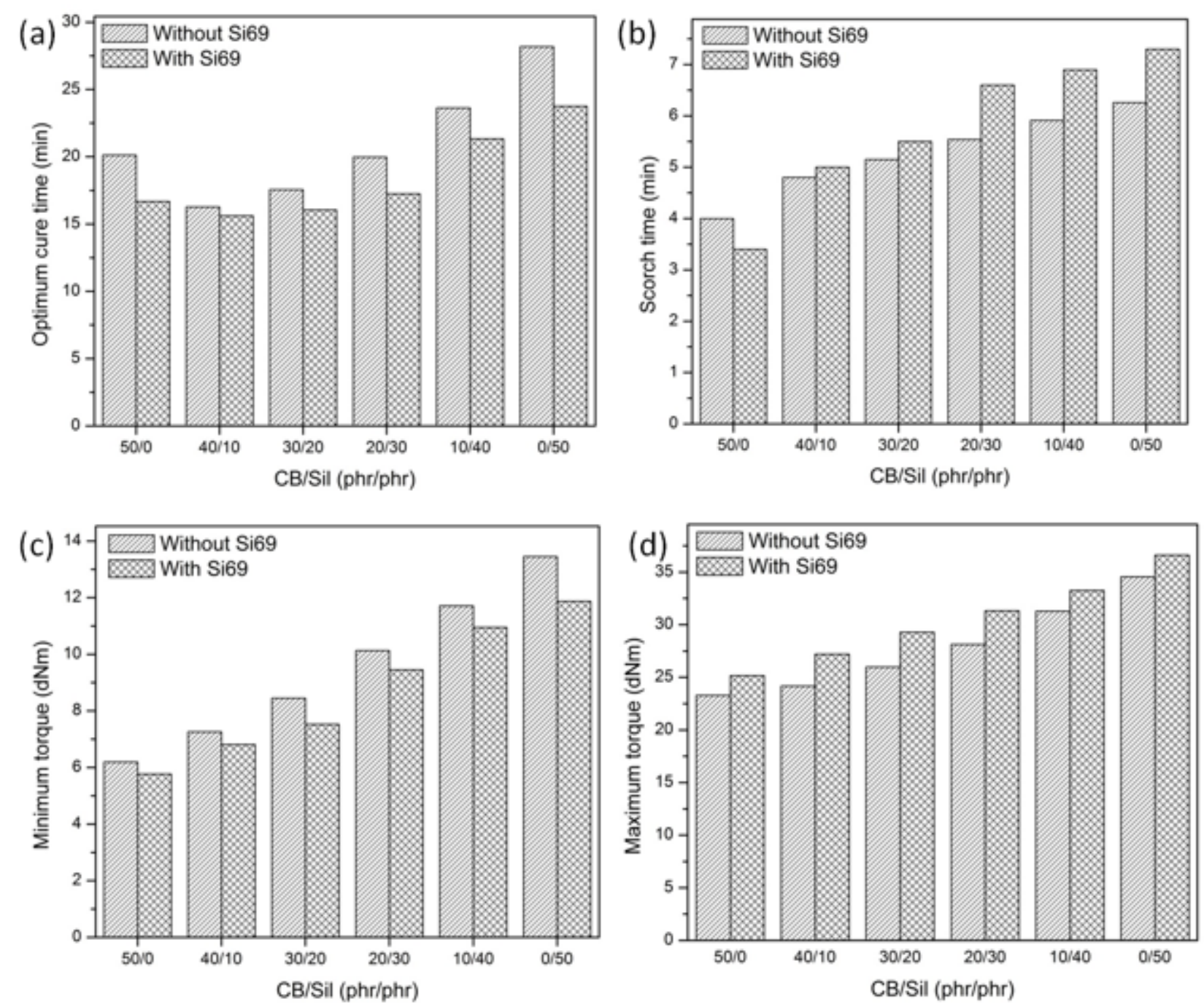

\section{Figure 1}

The cure characteristics of CB/Si hybrid filler filled NR/SBR composites with and without Si69: a) Optimum cure time, b) Scorch time, c) Minimum torque and d) Maximum torque. 


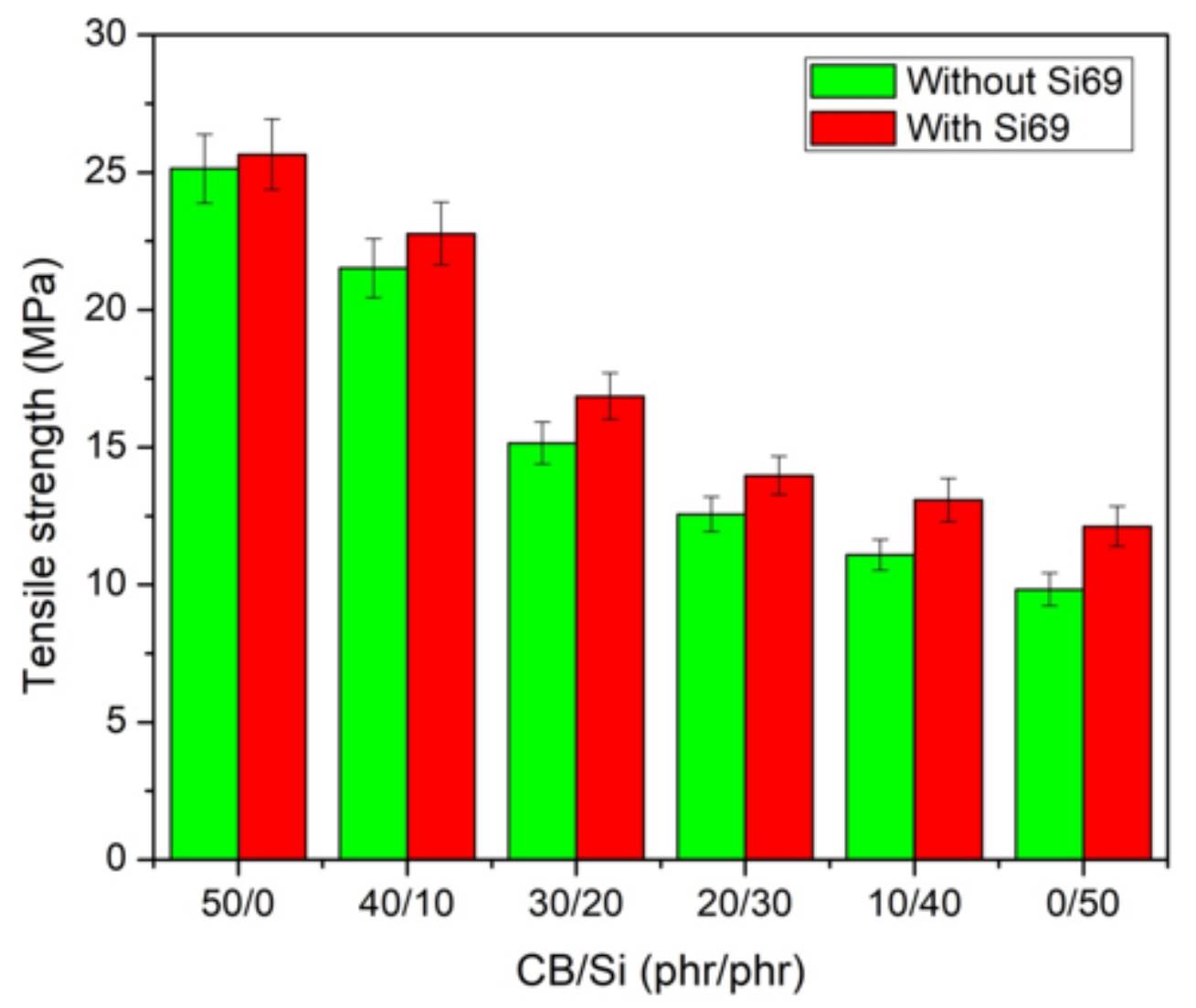

Figure 2

The tensile strength of CB/Si filler filled NR/SBR composites with and without Si69. 


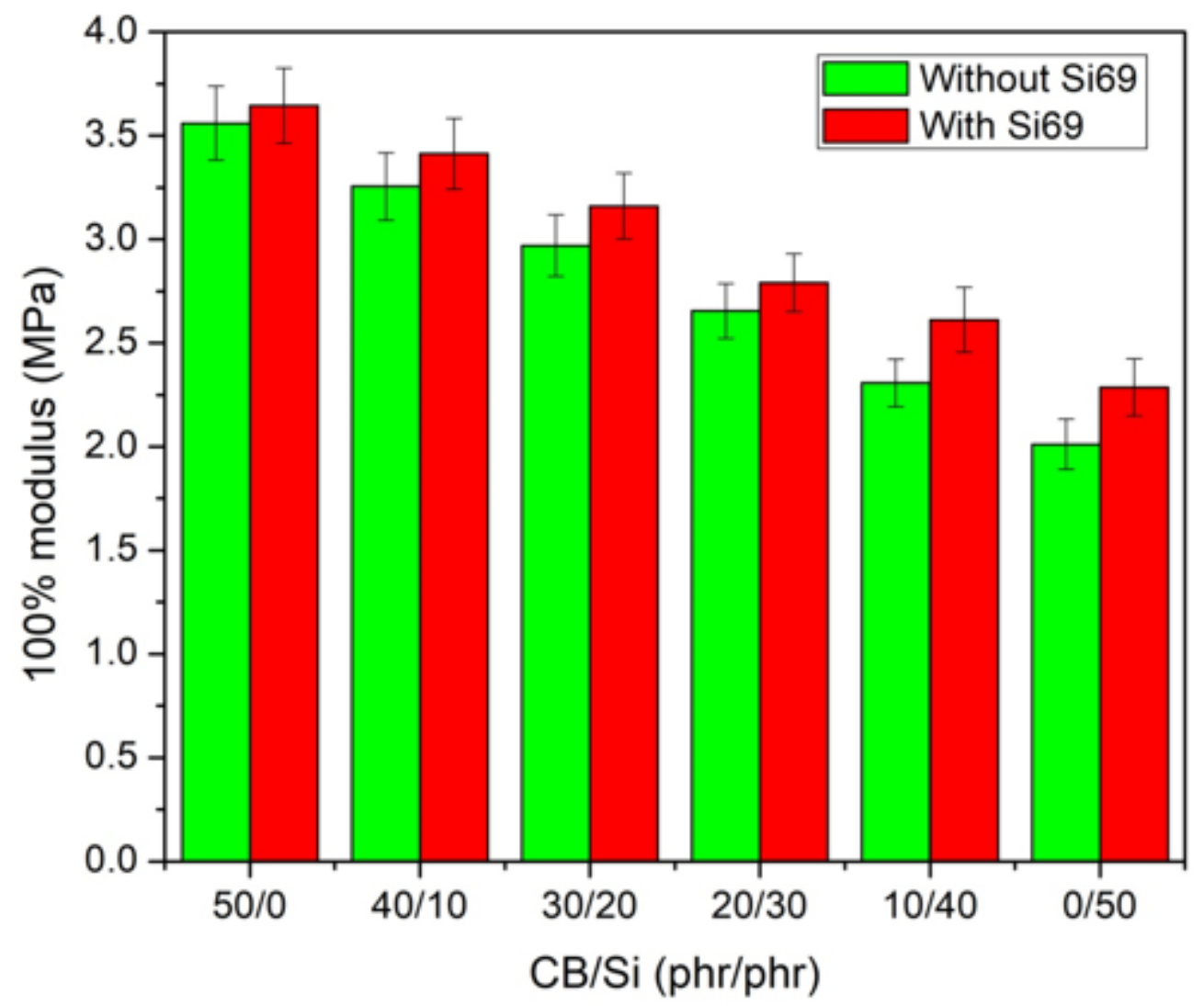

Figure 3

The $100 \%$ modulus of CB/Si filler filled NR/SBR composites with and without Si69. 


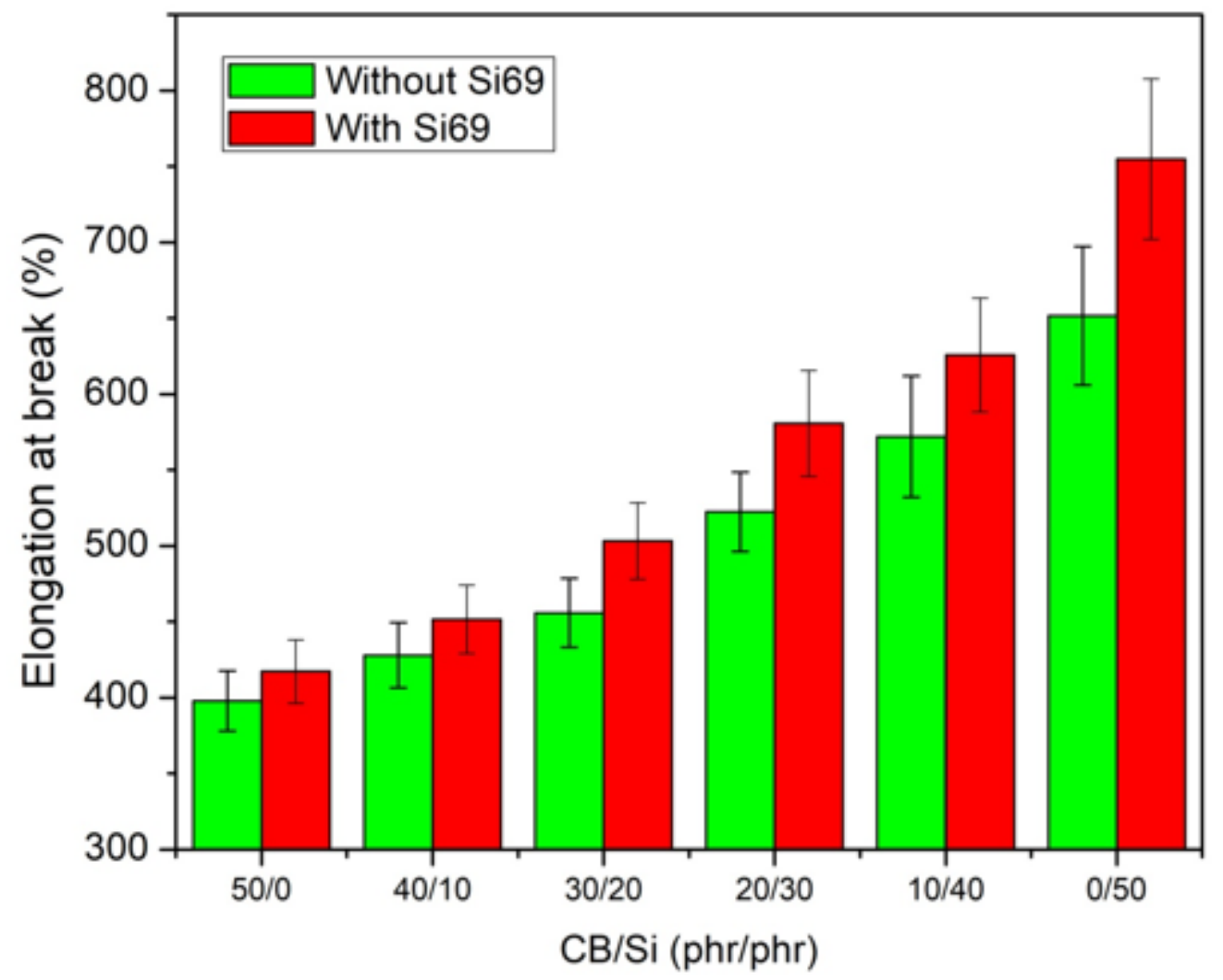

Figure 4

The elongation at break of CB/Si filler filled NR/SBR composites with and without Si69.

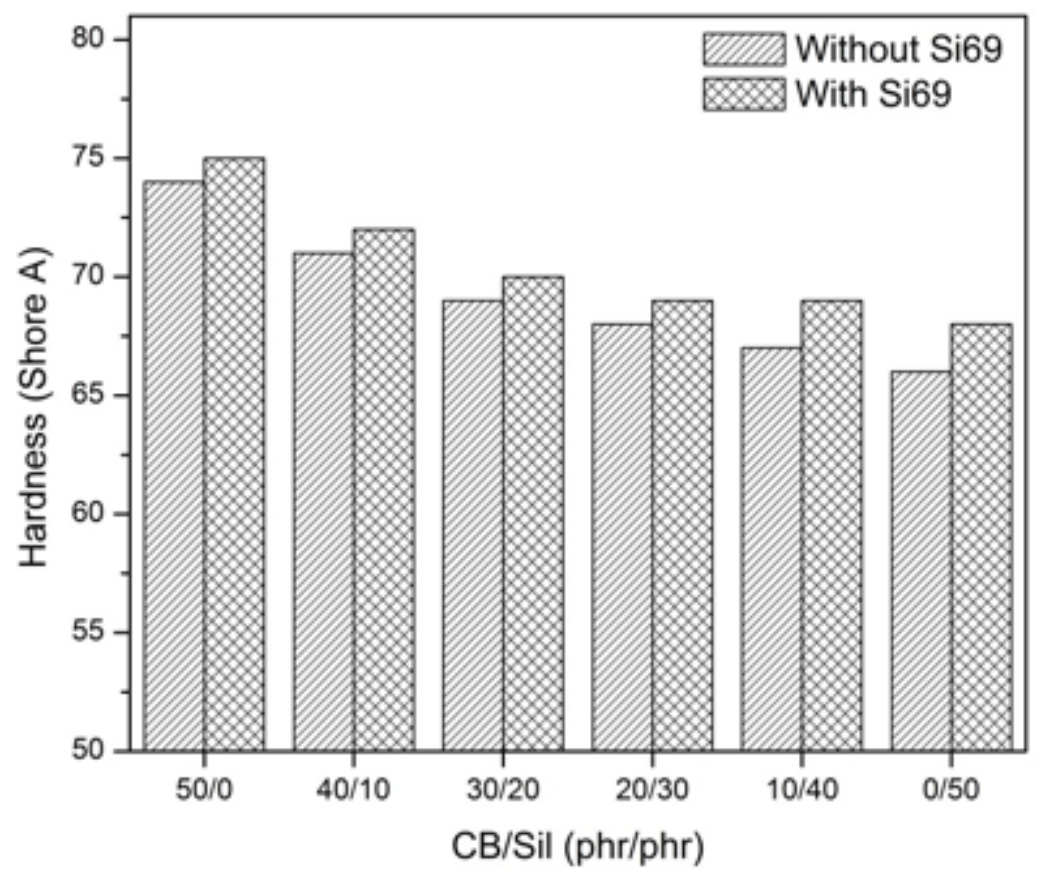

Figure 5 
The hardness of CB/Sifiller filled NR/SBR composites with and without Si69.

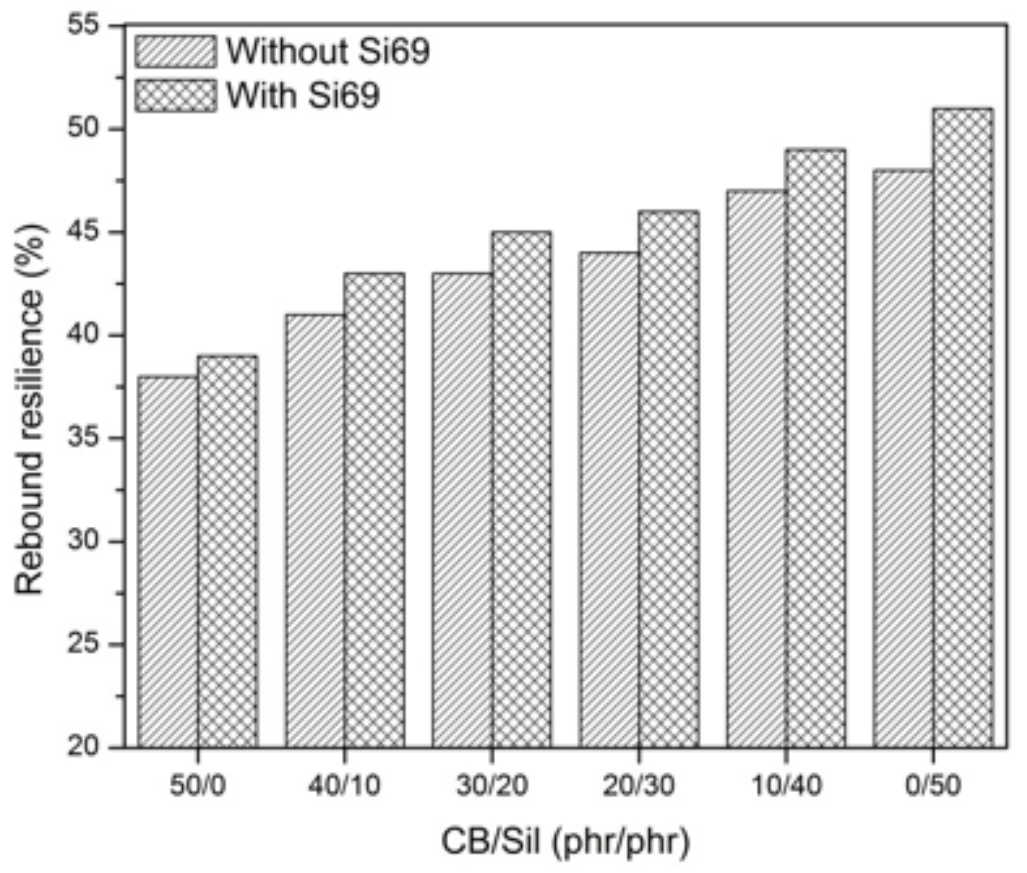

Figure 6

The rebound resilience of CB/Sifiller filled NR/SBR composites with and without Si69.

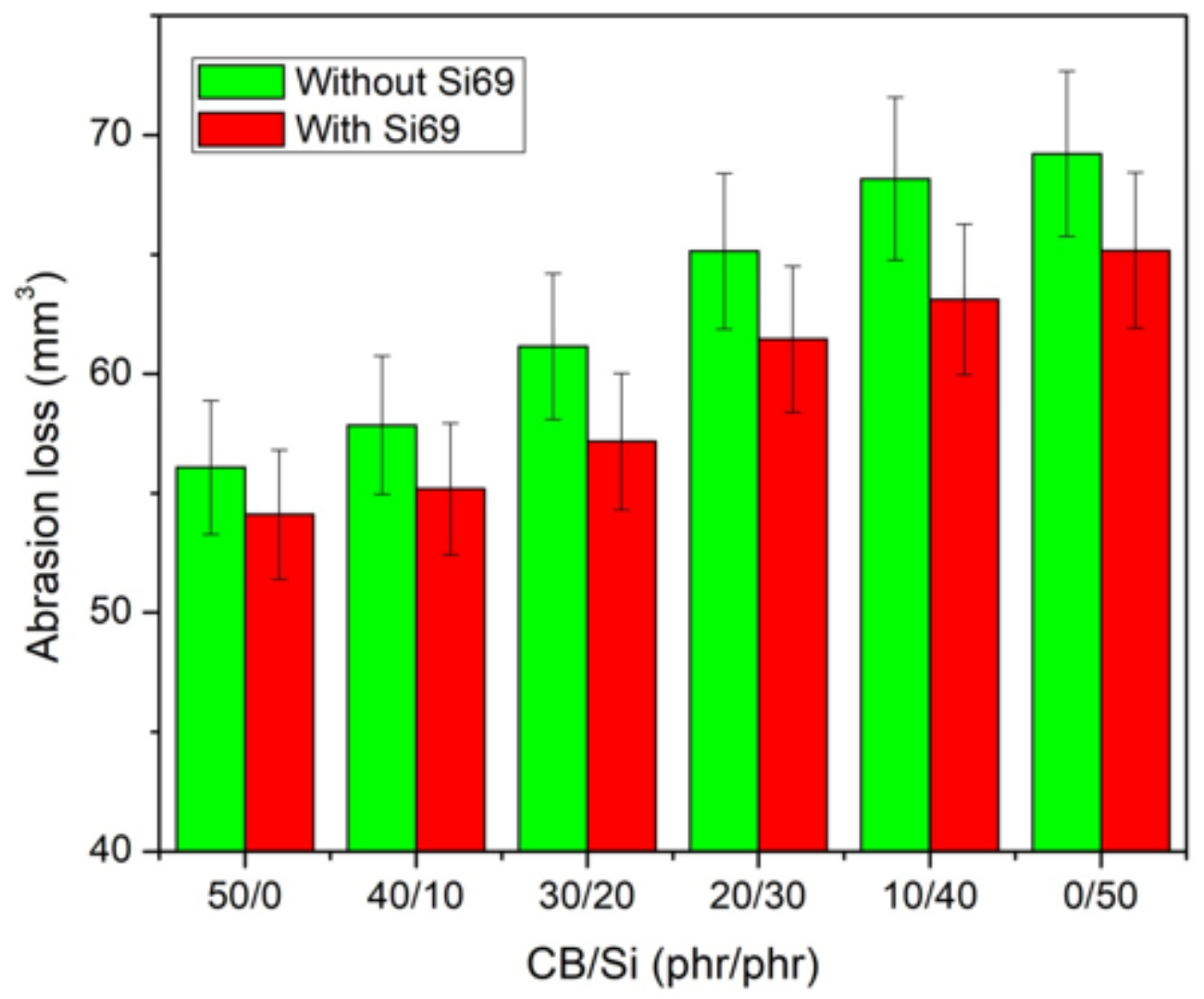

Figure 7 
The abrasion loss of CB/Si filler filled NR/SBR composites with and without Si69.

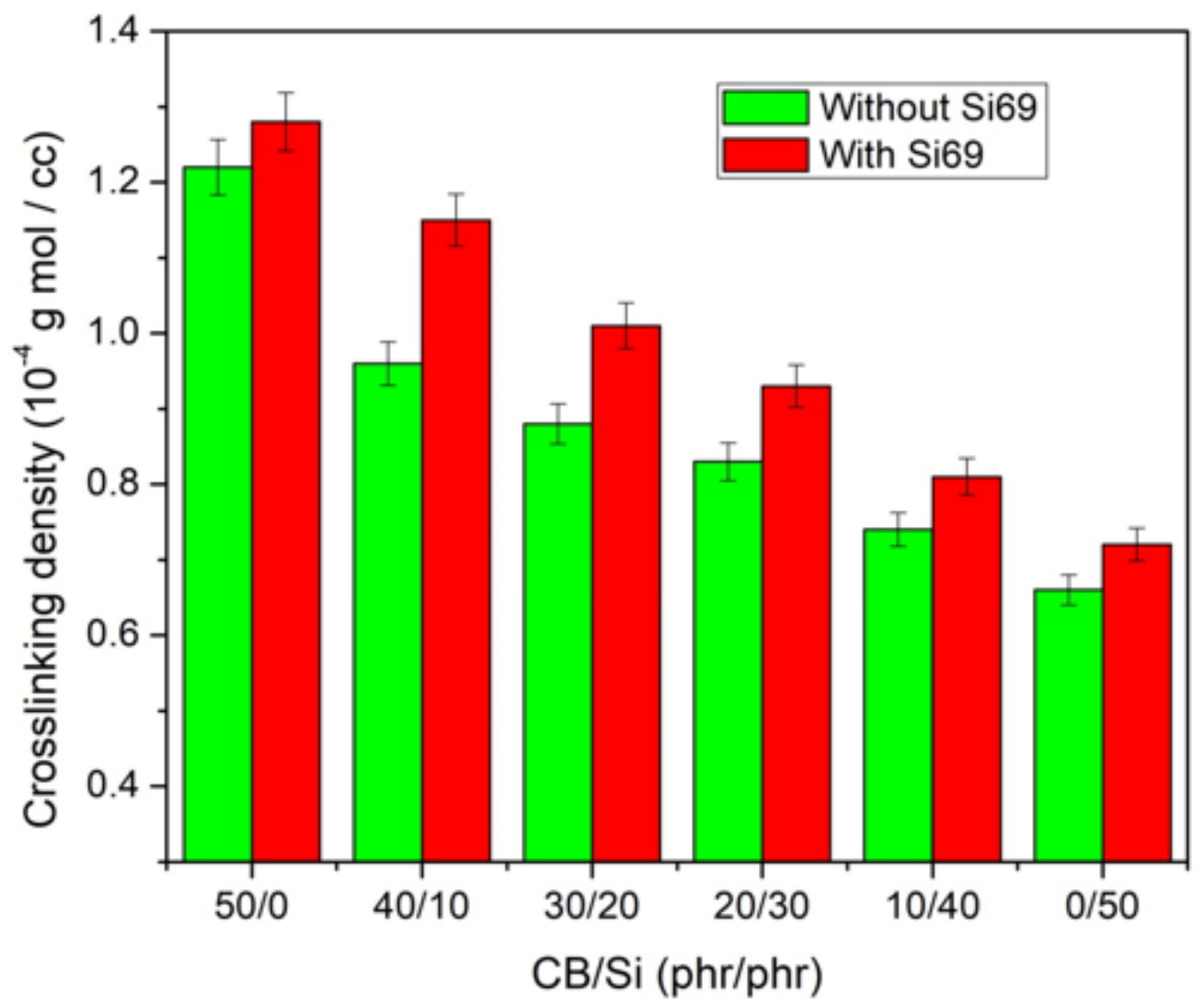

Figure 8

The crosslinking density of CB/Si filler filled NR/SBR composites with and without Si69.
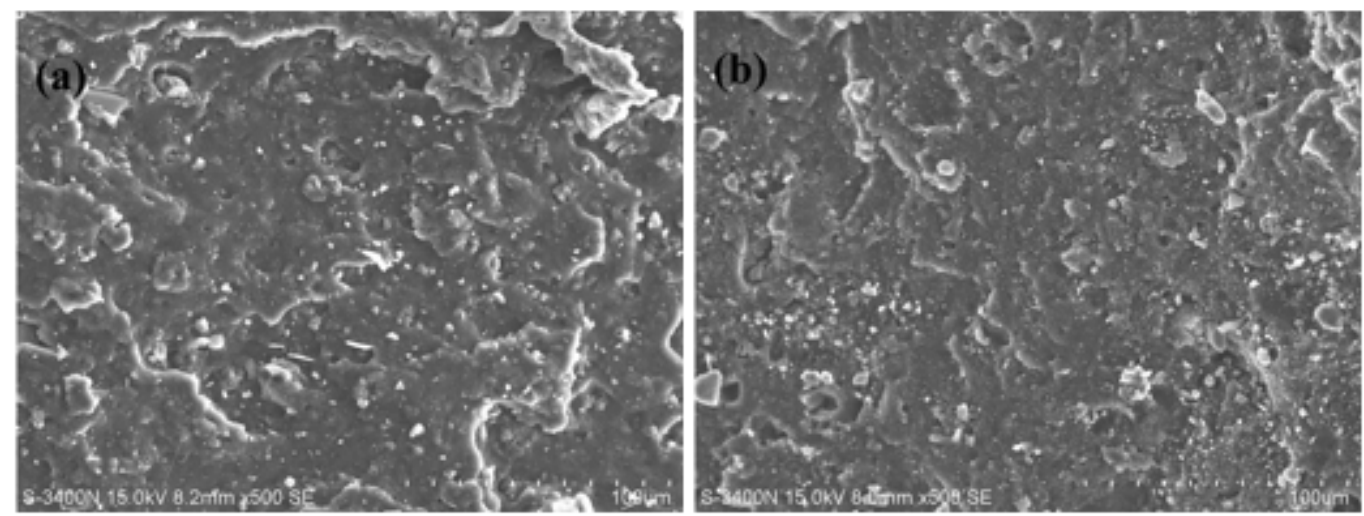

Figure 9

The tensile fracture surfaces of hybrid fillers filled NR/SBR composites with $\times 300$ magnification, (a) with silane coupling agent at 20/30 composite ratio, (b) without silane coupling agent at 20/30 blend ratio 